\title{
Hydrogels with a Memory: Dual-Responsive, Organometallic Poly(ionic liquid)s with Hysteretic Volume-Phase Transition
}

\author{
Kaihuan Zhang, ${ }^{\ddagger}$ Xueling Feng, ${ }^{\dagger, \ddagger}$ Chongnan Ye, Mark A. Hempenius, and G. Julius Vancso* \\ Materials Science and Technology of Polymers, MESA+ Institute for Nanotechnology, University of Twente, P.O. \\ Box 217, 750oAE, Enschede, the Netherlands \\ KEYWORDS: carbon nanotubes, hydrogels, LCST, poly(ferrocenylsilane)s, poly(ionic liquid)s
}

\begin{abstract}
We report on the synthesis and structure property relations of a novel, dual-responsive organometallic poly(ionic liquid) (PIL), consisting of a poly(ferrocenylsilane) backbone of alternating redox-active, silane bridged ferrocene units, and tetraalkylphosphonium sulfonate moieties in the side groups. This PIL is redox responsive due to the presence of ferrocene in the backbone, and also exhibits a lower critical solution temperature (LCST)-type thermal responsive behaviour. The LCST phase transition originates from the interaction between water molecules and the ionic substituents and shows a concentration-dependent, tunable transition temperature in aqueous solution. The PIL's LCSTtype transition temperature can also be influenced by varying the redox state of ferrocene in the polymer main chain. As the polymer can be readily cross-linked and is easily converted into hydrogels, it represents a new dual-responsive materials platform. Interestingly, the as-formed hydrogels display an unusual, strongly hysteretic volume-phase transition indicating useful thermal memory properties. By employing the dispersing abilities of this cationic PIL, CNT-hydrogel composites were successfully prepared. These hybrid conductive composite hydrogels showed bi-stable states and tunable resistance in heating-cooling cycles.
\end{abstract}

\section{- INTRODUCTION}

Stimuli-responsive, or "smart" soft materials have raised considerable attention due to their ability to spontaneously respond to external environmental variations, ${ }^{1-3}$ such as changes in temperature, $\mathrm{pH}$, solvent, pressure and magnetic or electric fields, showing promising potential applications in sensing, ${ }^{4}$ gating materials, ${ }^{5}$ actuators and molecular devices. ${ }^{6}$ Thus, design and synthesis of stimuli-responsive, multi-functional materials have received distinguished attention in polymer chemistry and materials science. ${ }^{7-9}$

Polymers with lower critical solution temperature (LCST)-type behavior are an important subclass of "smart" materials which exhibit a reversible conformation transition between coil and globule, stimulated by a thermal trigger. Poly( $N$-isopropylacrylamide) (PNIPAM) and their polyamide analogues are well-known examples. ${ }^{10,11}$ They are usually electrostatically neutral or weakly charged in aqueous solution. Poly(ionic liquid)s (PILs) bearing a quaternary phosphonium sulfonate ion pair obtained by the direct polymerization of corresponding monomers were introduced recently, as strong polyelectrolytes, broadening the design scope of thermo-responsive "smart" materials, with promising applications in desalination, selective absorption, responsive hydrogels, dispersants, and stabilizers. ${ }^{12-17}$
Poly(ferrocenylsilane)s (PFSs), composed of alternating ferrocene and silane units along the main chain, are a fascinating class of redox-active organometallic polymers featuring a high density of redox centers and excellent processability. ${ }^{18-21}$ The post-polymerization modification method is often employed in polymer synthesis to endorse the macromolecules with designer properties and diverse functionalities. ${ }^{22-24}$ In previous works, a variety of post-functionalized PFSs has been designed and prepared by substituting different side groups, e.g., acrylate, imidazolium, azide and poly(ethylene glycol) chains, yielding innovative functional organometallic polymer materials with desirable properties. ${ }^{25-30}$

In this paper, we demonstrate that the conjugation of thermo-responsive ionic liquid moieties with organometallic polymer backbones by postpolymerization modification would offer interesting opportunities for the synthesis and applications of tailormade, "smart" soft materials with unexpected responsive behavior. By using this strategy, we introduce novel dualresponsive PILs based on redox-active poly(ferrocenylsilane)s. Redox- and thermo-responsive PILs are used as building blocks to construct "smart" hydrogels which display surprising and interesting hysteretic volume-phase transitions with unexpected bistable states at room temperature. 


\section{- RESULTS AND DISCUSSION}

\section{Dual-responsive PILs}

As illustrated in Scheme 1, tetraalkylphosphonium side groups are introduced to PFS by a simple quaternization reaction between poly(ferrocenyl(3-iodopropyl) methylsilane) (PFS-I) and tri- $n$-butylphosphine $\left(\mathrm{PBu}_{3}\right)$ in a mixture of THF and DMSO, forming a new organometallic PIL, i.e. PFS-PBu $\mathrm{Pu}_{3}$. Iodide was exchanged with chloride or alkyl sulfonate counterions by dialysis in the corresponding aqueous salt solution. The resulting polymer was characterized by ${ }^{1} \mathrm{H}$ NMR spectroscopy, indicating the quantitative conversion of the iodopropyl groups of PFS-I into tetraalkylphosphonium groups, as was evident from the complete disappearance of the $\mathrm{CH}_{2}$ I signal in the ${ }^{1} \mathrm{H}$ NMR spectrum at $\delta=3.2 \mathrm{ppm}$. After adequate dialysis, successful exchange of the iodide counterions into pentanesulfonate $\left(\mathrm{C}_{5} \mathrm{~S}\right)$ counterions was also supported by ${ }^{1} \mathrm{H}$ NMR spectroscopy, revealing the signals typical of $\mathrm{C}_{5} \mathrm{~S}$ with the expected integrals (Figure S1, Supporting Information).

Scheme 1. Synthesis of dual-responsive PILs from a nucleophilic substitution reaction

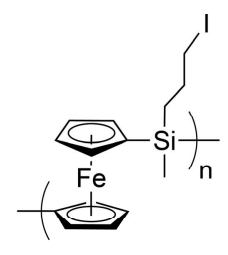

PFS-I

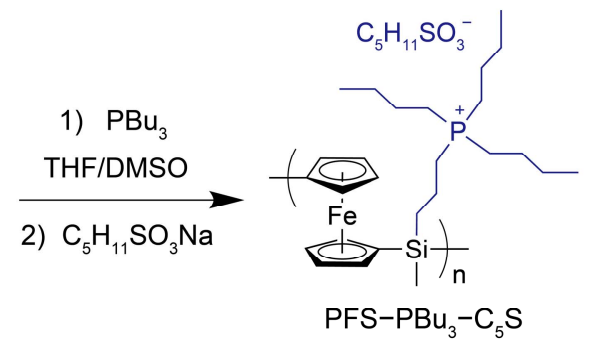

The counterion species strongly influences the PFS polyelectrolyte properties in water due to the hydrophobicity/hydrophilicity balance..132 When PFS$\mathrm{PBu}_{3}$ includes chloride as the counterion, the polymer can be well dissolved in water. In a recent report by Yuan and co-workers, a phosphonium-based cationic PIL containing an alkyl sulfonate anion was found to undergo a LCST-type phase transition in aqueous solutions. ${ }^{14}$ Here, the new PIL with structural similarity, the PFS-PBu bearing $\mathrm{C}_{5} \mathrm{~S}$ as counterion also displays an LCST-type phase transition when the temperature is raised (Figure S2, Supporting Information). The aqueous polymer solution of $\mathrm{PFS}-\mathrm{PBu}_{3}-\mathrm{C}_{5} \mathrm{~S}$ was transparent at room temperature and gradually turned into a yellow opaque suspension upon heating. The original transparent state of the solution could be recovered upon cooling back to room temperature.

The thermo-responsive properties of $\mathrm{PFS}-\mathrm{PBu}_{3}-\mathrm{C}_{5} \mathrm{~S}$ in water as a function of polymer concentration were studied first. Turbidity experiments revealed sharp and tunable LCST phase transition behavior of the PFS-PBu ${ }_{3}$ $\mathrm{C}_{5} \mathrm{~S}$ in water (Figure 1a). The cloud point temperature increased from $22{ }^{\circ} \mathrm{C}(8 \mathrm{wt} \%)$ to $49{ }^{\circ} \mathrm{C}$ (1 wt\%) upon gradual dilution (Figure $1 \mathrm{~b}$ ). In contrast to typical neutral thermo-responsive polymers, e.g., PNIPAM, which exhibit a cloud point temperature within a rather narrow range around $32{ }^{\circ} \mathrm{C}$, the phase transition temperature of most thermo-responsive PILs changes over a wide range depending on polymer concentration and the type and concentration of additional salts. This behavior is usually explained as a result of the structural balance between the alkyl sulfonate counterion with a hydrophobic hydrocarbon tail and the hydrophilic charged group..$^{33}$ a)

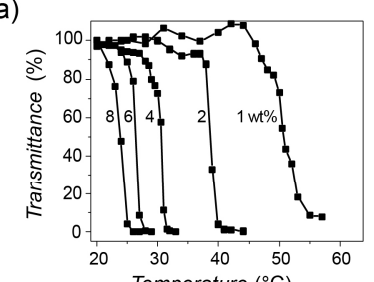

c)

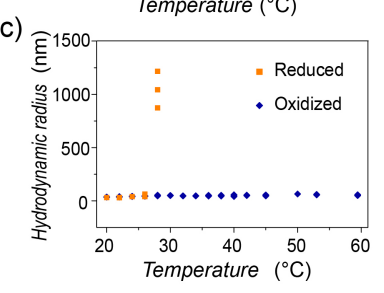

b)

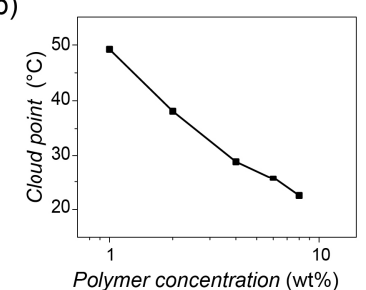

d)

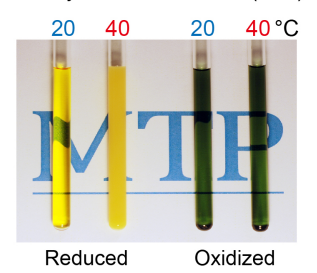

Figure 1. (a) Turbidity curves of PFS- $\mathrm{PBu}_{3}-\mathrm{C}_{5} \mathrm{~S}$ in aqueous solution at concentrations of $1,2,4,6$, and $8 \mathrm{wt} \%$. (b) Cloud points of $\mathrm{PFS}-\mathrm{PBu}_{3}-\mathrm{C}_{5} \mathrm{~S}$ in aqueous solution at different concentrations. (c) DLS measurements of dual-responsive PIL in reduced (1 wt $\%$ PFS- $\mathrm{PBu}_{3}-\mathrm{Cl}, 40 \mathrm{mM} \mathrm{NaC}{ }_{5} \mathrm{~S}$ with 60 $\mathrm{mM} \mathrm{NaCl}$ ) and oxidized (1 wt\% PFS-PBu $-\mathrm{Cl}, 40 \mathrm{mM} \mathrm{NaC} \mathrm{C}_{5} \mathrm{~S}$ with $20 \mathrm{mM} \mathrm{FeCl}_{3}$ ) states. (d) Photographs of reduced and oxidized PIL at $20^{\circ} \mathrm{C}$ and $40^{\circ} \mathrm{C}$, respectively.

Due to the presence of the ferrocene units in the PFS main chain, the corresponding organometallic poly(ionic liquid)s display redox-responsive behavior. The polymer shows a reversible color change from amber to dark green upon oxidation (Figure 1d). The reduced PFS exhibits an absorbance peak at $450 \mathrm{~nm}$, corresponding to a characteristic d-d electronic transition (Figure Sza, Supporting Information). After oxidation, a new peak at $635 \mathrm{~nm}$ appears due to the formation of ferrocenium cations. Regarding the redox behavior, typical double wave-shaped voltammetry signals, representative of PFSs were observed (Figure S3b, Supporting Information) demonstrating redox-responsiveness originating from ferrocene in the polymer main chain and electronic $\mathrm{p} \pi-\mathrm{d} \pi$ coupling between neighboring ferrocene units via $\mathrm{Si}$ bridges. 34,35

The excess positive charge along the PFS main chain from chemical or electrochemical oxidation increases the overall hydrophilicity, which results in a redox-switchable thermo-responsive behavior. As shown in Figure $1 d$, the solution of neutral, or reduced, polymer turned turbid upon elevating the temperature, while the oxidized polymer remains clear upon heating, i.e., the LCST phase transition is absent. In order to explain this redoxswitchable behavior, temperature-dependent dynamic light scattering (DLS) experiments were conducted on samples with constant polymer concentration (Figure 1c). The counterion species and their concentration were 
carefully controlled to remain identical in both reduced and oxidized samples, ruling out the influence of the counterion composition. The values of the hydrodynamic radii of the polymer particles in aqueous solution are displayed in Figure 1c. At room temperature, the solution contains molecularly dissolved polymer chains with some very small residual fraction of aggregates with diameter $<100 \mathrm{~nm}$. Upon heating, the primary soluble aggregates slightly grow at lower temperatures and suddenly jumpincrease in size at $29{ }^{\circ} \mathrm{C}$, while the chain dimensions of the oxidized state sample remain essentially unchanged. This transition is confirmed by turbidity measurements (Figure $\mathrm{S}_{4}$, Supporting Information), illustrating that the

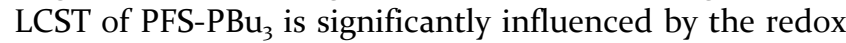
state of the PFS main chain. During oxidation, the polymer main chains become positively charged and the backbones are highly strained due to the increased Kuhn length and segment elasticity, ${ }^{36-38}$ which inhibits the torsion and rotation of the side groups that would promote aggregate forming. The hydrophilicity of the polymer backbones also increases with oxidation, influencing the hydrophobicity-hydrophilicity balance in the aqueous polymer system. The combined action of these effects suppresses the LCST transition.

\section{Dual-responsive PILs-based hydrogel}

Acrylate or acrylamide moieties allow rapid and quantitative uniform cross-linking under mild conditions by thiol-Michael addition reactions. ${ }^{25} \mathrm{~N}-[3-$ (Dimethylamino)propyl] methacrylamide (DMAPMA) was introduced to the PFS backbone to obtain a crosslinkable dual-responsive polymer prior to the addition of $\mathrm{PBu}_{3}$ (Figure 2a and Experimental Section). Defined quantities of DMAPMA $(0.45,0.25,0.15$, and 0.08 in repeat unit molar ratio) were incorporated by reaction of PFS-I with this monomer.

Reaction between PFS-I and DMAPMA was proved by FTIR and ${ }^{1} \mathrm{H}$ and ${ }^{13} \mathrm{C}$ NMR spectroscopy (Figure $\mathrm{S}_{5}, \mathrm{~S} 6$ and $\mathrm{S}_{7}$, Supporting Information). Because of the presence of DMAPMA, the organometallic polymers can be transformed into dual-responsive PIL networks. Hydrogels were prepared from PFS-DMAPMA- $\mathrm{PBu}_{3}$ and 4-arm PEG-thiol with pentaerythritol core by the rapid and quantitative thiol-Michael addition reaction under mild conditions (Figure $2 \mathrm{~b}$ and c). Subsequently, the hydrogels obtained were characterized.

The water content in the hydrogels was determined to be $95 \mathrm{wt} \%$ for $\mathbf{H}_{3}$. The mechanical properties of $\mathbf{H}_{\mathbf{1}}, \mathbf{H}_{\mathbf{2}}$ and $\mathbf{H}_{3}$ were evaluated by dynamic mechanical measurements, indicating the elastic nature of the hydrogel networks. The storage modulus did not depend on the frequency in the employed frequency range between 0.06 and $60 \mathrm{rad} / \mathrm{s}$ (Figure S8, Supporting Information). The mechanical data obtained show that the hydrogels can be considered as a "hard gel" $\left(G^{\prime}>1 \mathrm{kPa}\right)$ according to Hvidt's classification. ${ }^{39,40}$ a)

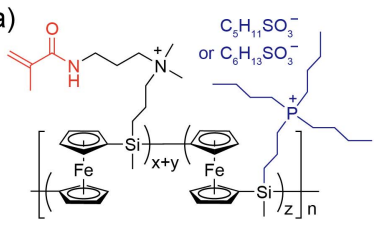

Cross-linkable PFS-DMAPMA-PBu

c)

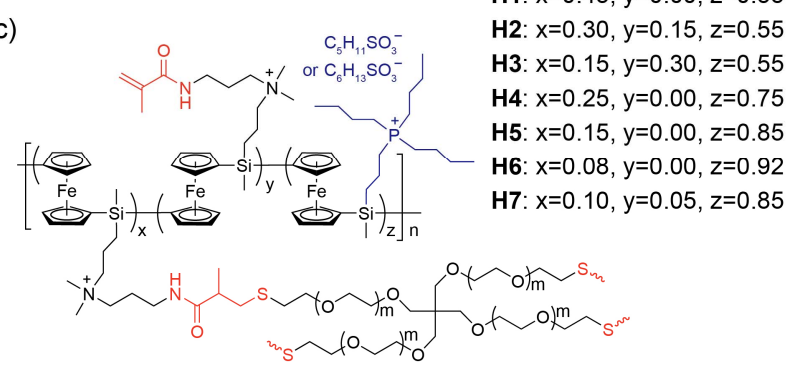

Figure 2. (a) Schematic representation of cross-linkable PFSDMAPMA-PBu ${ }_{3}$. (b) Photographs of PFS-based dualresponsive hydrogels formed by using a 4-arm PEG-thiol cross-linker. (c) Hydrogel composition $\left(\mathbf{H}_{\mathbf{1}} \sim \mathbf{H}_{7}\right)$ based on PFS-DMAPMA-PBu ${ }_{3}$ and 4-arm PEG-thiol cross-linker with different cross-linking degree $(\mathrm{x})$ and $\mathrm{DMAPMA} / \mathrm{PBu}_{3}$ ratio $(\mathrm{x}+\mathrm{y}: \mathrm{z})$.

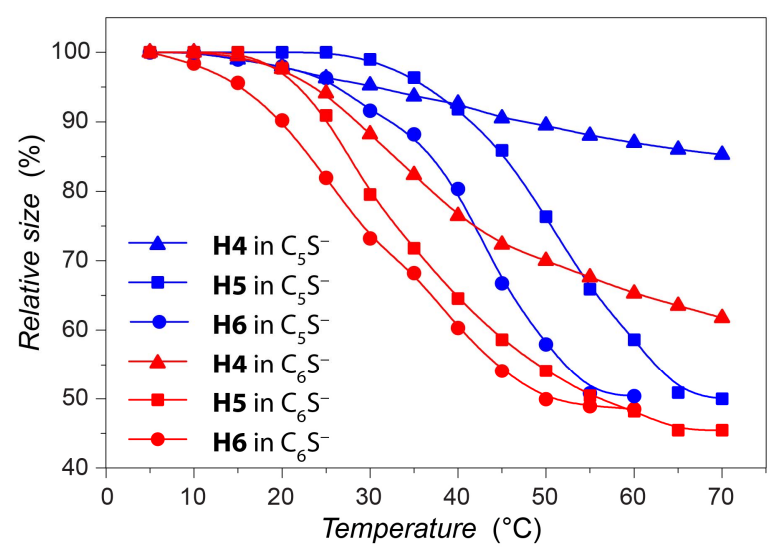

Figure 3. Volume-phase transition of hydrogel $\mathrm{H}_{4}(25 \% \mathrm{CD})$, $\mathrm{H}_{5}(15 \% \mathrm{CD})$, and $\mathbf{H 6}(8 \% \mathrm{CD})$ in $5 \mathrm{mM} \mathrm{NaC}_{5} \mathrm{~S}$ and $\mathrm{NaC}_{6} \mathrm{~S}$ aqueous solutions. Midpoint of volume-phase transition: 51 ${ }^{\circ} \mathrm{C}\left(\mathrm{H}_{5}\right.$ in $\left.\mathrm{NaC}_{5} \mathrm{~S}\right), 42{ }^{\circ} \mathrm{C}\left(\mathrm{H}_{6}\right.$ in $\left.\mathrm{NaC}_{5} \mathrm{~S}\right)$; $34{ }^{\circ} \mathrm{C}\left(\mathrm{H}_{5}\right.$ in $\left.\mathrm{NaC}_{6} \mathrm{~S}\right)$, $29{ }^{\circ} \mathrm{C}\left(\mathrm{H} 6\right.$ in $\left.\mathrm{NaC}_{6} \mathrm{~S}\right)$.

Similar to the phase transition of non-crosslinked PFS$\mathrm{PBu}_{3}$ in aqueous solution, the hydrogels obtained from the organometallic PILs also show LCST-type thermoresponsive behavior. The transition temperature could be tuned by varying the cross-linking degree $(\mathrm{CD})$ and the choice of the counterion species in the hydrogel, which influence the hydrophobicity/hydrophilicity balance in the systems (Figure 3). For the hydrogel with $\mathrm{C}_{5} \mathrm{~S}$ counterions, the transition temperature increases from 42 ${ }^{\circ} \mathrm{C}(8 \% \mathrm{CD})$ to above $50{ }^{\circ} \mathrm{C}(15 \% \mathrm{CD})$. For the specimen with the highest cross-link density (25\%) the transition became very broad, thus no clear LCST could be defined. However, it is clear that further shifts of the LCST value with increasing $\mathrm{CD}$ takes place. We postulate that the shape of the volume-phase transition is sharper at lower 
$\mathrm{CD}$, resulting from the higher degree of motional freedom of network chains between cross-link junctions for lower CD values. ${ }^{41}$

The length of the carbon chain in the counterion is another factor that influences the LCST behavior of the PILs. ${ }^{14}$ When using hexanesulfonate $\left(\mathrm{C}_{6} \mathrm{~S}\right)$ as the counterion, the hydrogel shows a similar trend in the transition behavior, while the values of the transition temperature decrease to $29{ }^{\circ} \mathrm{C}$ (at $8 \% \mathrm{CD}$ ), and $34{ }^{\circ} \mathrm{C}$ (at $15 \% \mathrm{CD}$ ) at the same sulfonate concentration. (We note that for $25 \% \mathrm{CD}$ the transition is also broad, similar to $\mathrm{C}_{5} \mathrm{~S}$.) We conclude that by carefully choosing the counterion species and the cross-linking degree, the transition behavior of the PFS-PIL hydrogels could be fine-tuned in a wide range of temperatures.

The hydrogels could also be reversibly oxidized and reduced both chemically and electrochemically. Figure $4 \mathrm{a}$ captures the variations of the relative diameter of diskshaped specimens of hydrogel $\mathbf{H}_{3}$ in their reduced and oxidized states. The dimensional changes of representative reduced, as well as oxidized, specimens are shown on the photographs in Figure $4 \mathrm{~b}$. The reduced and oxidized samples display the typical color change characteristic for PFS upon changing its redox state (Figure $4 \mathrm{~b}$ ). The dimensional changes upon heating from $20{ }^{\circ} \mathrm{C}$ to $70{ }^{\circ} \mathrm{C}$ are also visible, while the extent of the shrinkage of the oxidized sample is substantially smaller upon heating. Quantitative data for dimensional variations (Figure 4a) capture this difference. At room temperature, the swelling ratio of the orange-color hydrogel had a value of 19 , while the value for the oxidized (dark green) specimen was 45 . This difference in volumetric swelling ratio indicates a variation of the overall polarity of the gel, which changes during the redox reaction. ${ }^{25,42}$

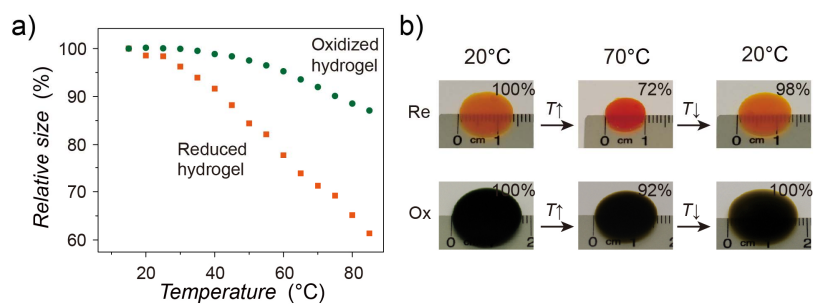

Figure 4. Dimensional variations of the reduced and oxidized hydrogels vs. temperature. (a) Variation of the relative size of the reduced and oxidized hydrogel $\mathbf{H}_{3}$ in 45 $\mathrm{mM} \mathrm{NaC} 5$ S aqueous solution (heating rate: $0.1{ }^{\circ} \mathrm{C} \mathrm{min}^{-1}$ ). Hydrogel $\mathrm{H}_{3}$ was oxidized in $45 \mathrm{mM} \mathrm{NaC}_{5} \mathrm{~S}$ and $40 \mathrm{mM}$ $\mathrm{FeCl}_{3}$, then equilibrated in $45 \mathrm{mM} \mathrm{NaC} 5$ S aqueous solution before measurements. (b) Photographs of the reduced (top) and oxidized (bottom) hydrogel $\mathbf{H}_{3}$ upon heating and cooling.

We note, that due to the presence of the oxidized ferrocenium moieties, the polycation chain acquired additional positive charge from the oxidation that increased the hydrophilicity of the chain, which weakened the volume change.

\section{Hysteretic behavior of PFS PIL-based hydrogels}

In addition to the redox-switchable thermo-responsive volume-phase behavior, surprisingly, the neutral, or reduced, PFS-DMAPMA-PBu ${ }_{3}$ hydrogel exhibits a strongly hysteretic volume-phase transition and shows long-lived bi-stable states at room temperature (Figure 5a). Hysteresis is an interesting phenomenon, displaying output that depends on both present and past input. Usually occurring in ferromagnetic and ferroelectric materials, hysteresis has also been found in the soft matter field, especially in stimuli-responsive soft materials. ${ }^{43-52}$ For example, PNIPAM has hysteretic differences between heating and cooling of about $5{ }^{\circ} \mathrm{C} .{ }^{11}$ Previous reports often considered the hysteretic volumephase transitions as problematic because it affects signal reproducibility in many conventional applications. ${ }^{43}$ This behavior was also shown to be short-lived and fades as time passes. ${ }^{44,45}$ Such hysteretic volume-phase transitions in soft materials could be utilized for example in memory devices, where multiple states of the material can exist, preserving information of physical history in a single environment. ${ }^{46-51}$ Few examples of $\mathrm{pH}$-responsive polymer gels with hysteretic volume-phase transitions and strong bi-stability can be found in literature.43,46 The organometallic PIL hydrogel presented here provides a unique example of a thermo-responsive hysteretic system.

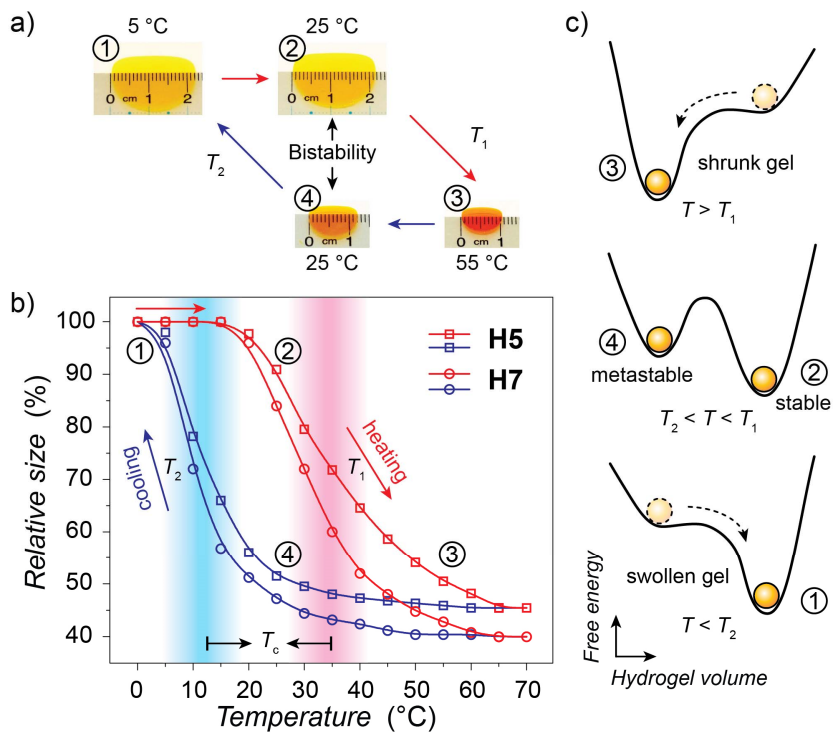

Figure 5. (a) Photographs of the shrinking and swelling of the PFS PIL-based hydrogel in a heating-cooling cycle, showing thermal hysteresis behavior and bi-stable states at $25{ }^{\circ} \mathrm{C}\left(\mathbf{H}_{7}\right.$, stable for more than 5 days). (b) Hysteresis loops of PFS PILs-based hydrogel $\mathbf{H}_{\mathbf{5}}, \mathbf{H}_{\mathbf{7}}$ in $5 \mathrm{mM} \mathrm{NaC}_{6} \mathrm{~S}$ aqueous solution (heating and cooling rates: $\left.0.1{ }^{\circ} \mathrm{C} \min ^{-1}\right), T_{1}, T_{2}$ : volume $^{-}$phase transition temperature in the heating-cooling cycle. $T_{c}$ : "coercivity" temperature. (c) Schematic illustration of the hydrogel sample's free energy at high temperature (3)), room temperature (2) and (4)), and low temperate (1). The coexistence is stable in the local energy minimum at $T_{2}<T<T_{1}$. 
In order to assess the hysteretic behavior, the size of the hydrogel was recorded during a relatively slow heatingcooling cycle using a rate of $0.1{ }^{\circ} \mathrm{C} \mathrm{min}^{-1}$. The relative size vs temperature curves obtained for two hydrogels are displayed in Figure $5 \mathrm{~b}$. In the heating curve, the size decreased significantly between $25{ }^{\circ} \mathrm{C}$ and $50{ }^{\circ} \mathrm{C}$ and remained constant at temperatures $\mathrm{T}>50{ }^{\circ} \mathrm{C}$. In the cooling curve, the relative size showed a clear hysteresis, as the size of the hydrogel remained almost constant until $25{ }^{\circ} \mathrm{C}$. With further cooling, the hydrogel swelled sharply. By keeping the samples at $5{ }^{\circ} \mathrm{C}$ overnight, the hydrogel could be recovered to its original size. This strong and unexpected hysteresis was shown to be persistent as the hydrogels with history information at states (2) and (4) (Figure 5a) were stable for at least 5 days at room temperature $\left(25^{\circ} \mathrm{C}\right)$.

The absence of hysteresis (less than $3{ }^{\circ} \mathrm{C}$ ) in uncrosslinked polymer solution (Figure S9, Supporting Information) implies a quick dissociation of the PIL aggregates into individual polymer chains. The hysteretic behavior of the hydrogel originates from the constrained nature of the polymer network and the concentrationdependent thermo-responsive phase transition as observed for uncross-linked polymer solution. Multiple phases can coexist in the gel if each corresponds to a local minimum in free energy (Figure $5 \mathrm{c}$ ). ${ }^{48,53}$ The swollen hydrogel at low temperature has a swelling ratio around 100 before heating, and thus a higher LCST. With the size decreasing, the local polymer concentration in the hydrogel matrix increases during shrinking, which results in a lowering of the LCST. In other words, the dehydration process of the hydrogel provides a positive feedback and promotes the lowering of the LCST value. Once the hydrogel reaches its final shrunken state at high temperature, its LCST will be reduced due to its low swelling ratio $(\sim 10)$. There is also a positive feedback related to the dehydration during the swelling process upon cooling.

In our experiments, two transition temperature values, $T_{1}$ and $T_{2}$, can be estimated from the midpoints of the volume $^{-}$phase transitions in the heating-cooling cycle, respectively (Figure $5 \mathrm{~b}$ ). A “coercivity" temperature, $T_{c}=$ $\left|T_{1}-T_{2}\right|$, has been introduced here to define the magnitude of residual temperature needed in the heatingcooling cycle to bring the hydrogel back to the original state. The "coercivity" temperatures for hydrogel $\mathbf{H}_{\mathbf{5}}$ and $\mathrm{H}_{7}$ are both approximately $20{ }^{\circ} \mathrm{C}$ covering the room temperature region. Once temperature crosses $T_{1}$ or $T_{2}$, the hydrogel can reach its final shrunken, or swollen, state even at the constant temperature as a result of the diminished coexistence phase and shifted energy minimum.

\section{Bi-stable CNT-hydrogel composites}

By combining with other functional materials, the applications of "smart" hydrogels can be extended. Here we demonstrate some application potential related to the ionic liquid nature of our starting polymers. PFSDMAPMA-PBu ${ }_{3}$ is a powerful dispersant, as are other

cationic PILs reported. ${ }^{54-56}$ We selected carbon nanotubes as conductive filler to be dispersed, due to their frequently utilized applications in electronic or sensing devices. Figure $6 a$ illustrates that CNTs are successfully suspended in aqueous solution with the aid of PFSDMAPMA-PBu ${ }_{3}$ after 30 min of ultrasound treatment in an ice bath. The macroscopic homogenous solution was stable for more than ten months (Figure S1o, Supporting Information), while the CNTs without the dispersing PIL precipitated in water completely overnight. The stabilizing effect is believed to come from a cation $-\pi$ electron interaction between the substituted phosphonium/ammonium groups and the CNTs surface (Figure S11, Supporting Information). ${ }^{56,57}$

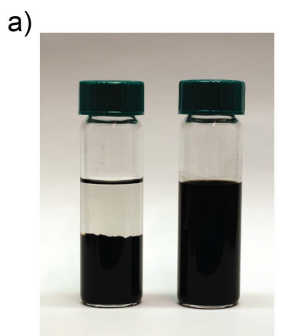

b)
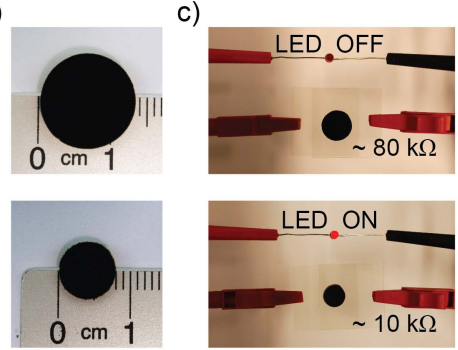

d)
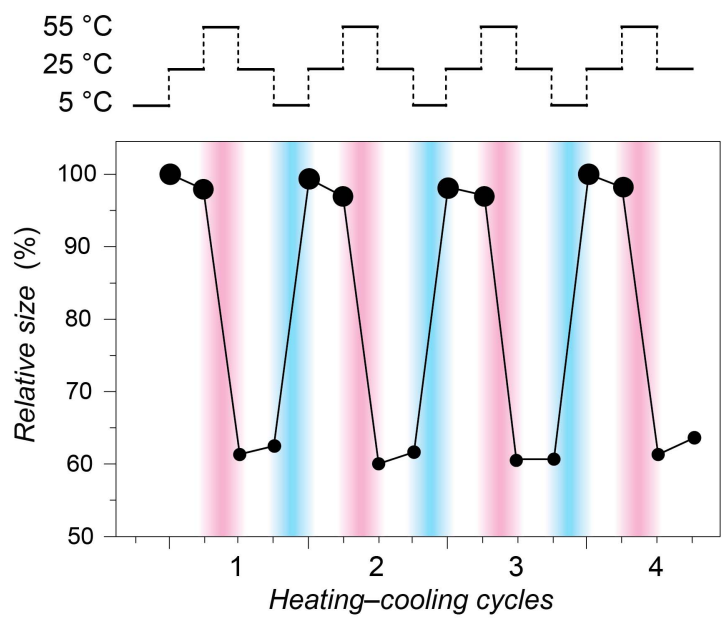

Figure 6. (a) A photograph of an aqueous dispersion of CNTs (10 $\mathrm{mg} / \mathrm{mL})$ with and without PFS-DMAPMA-PBu ${ }_{3}$ (5 $\mathrm{mg} / \mathrm{mL}$ ) taken 3 days after ultra-sonication treatment. (b) Bistable PFS-PEG/CNT hybrid hydrogels at room temperature (top: after cooling treatment, bottom: after heating treatment). (c) An on-off LED switch showing the hybrid hydrogel exhibiting different resistance values at swollen (top) and shrunken (bottom) states. (d) Relative size of PFSPEG/CNT hybrid hydrogel vs heating and cooling cycles.

PFS-PEG-based conductive hydrogels can be fabricated using our PILs loaded with CNTs. For practical applications, the resistance of the hydrogel, which depends on CNT concentration, can be controlled by the volume change that accompanies the LCST behavior of the hydrogel. As we demonstrate here, PFS-PEG/CNT hybrid hydrogels can show bi-stable states and tunable resistance upon heating and cooling. The amount of CNTs in the CNT-hydrogel composite was calculated to be $2 \mathrm{wt} \%$ and $11 \mathrm{wt} \%$, respectively, for swollen and shrunk 
hydrogels. Figure $6 \mathrm{~b}$ shows a stable size change of swollen and shrunk hydrogels that exhibit two different resistance values (approximately $80 \mathrm{k} \Omega$ and $10 \mathrm{k} \Omega$ ). The increase in resistance of the swollen hydrogel is due to an expanded CNT-hydrogel network, which leads to a reduction in the total number of conduction paths. ${ }^{58}$ In this proof-of-concept experiment, a piece of a PFS-PEGbased conductive hydrogel disk was placed between two parallel ITO substrates and connected to a red light emitting diode (LED) and a DC power supply with an output voltage of $2 \mathrm{~V}$ via an external electrical circuit. The volume-phase transition is well reproducible, as demonstrated by the four heating-cooling cycles captured in Figure $6 \mathrm{~d}$. The on/off state of the LED controlled by the different resistance of the piece of the hydrogel at room temperature is illustrated in Figure 6c, demonstrating the bi-stable behavior.

\section{- CONCLUSIONS}

In conclusion, by using a post-polymerization modification method, a dual-responsive organometallic polymer $\mathrm{PFS}-\mathrm{PBu}_{3}$ was synthesized using iodopropylsubstituted starting polymers. Tri- $n$-butylphosphine and alkanesulfonate anions were introduced to the side groups of PFS, yielding PILs with LCST-type behavior. The values of the LCST transition temperature could be tuned by the redox state of the polymer, by the concentration, and the choice of the compensating anions. By means of thiol-Michael addition cross-linking chemistry, the PILs were covalently connected to obtain hydrogels. These gels showed redox-switchable shrinking and swelling in response to thermal stimuli. The PFS-PEG hydrogel exhibited a strongly hysteretic volume-phase transition with a "coercivity" temperature of around $20{ }^{\circ} \mathrm{C}$ and showed bi-stable states at room temperature. In feasibility experiments the polymers were used as dispersant for CNTs and as building blocks for hybrid conducting hydrogels with CNTs. Potential applications showing a thermal memory character were illustrated by LED switching based on the variable resistance of the CNT-hydrogel composite. This new class of PIL and PILbased hydrogels is expected to open new opportunities in the field of functional soft materials.

\section{- EXPERIMENTAL METHODS}

Materials. Poly(ferrocenyl(3-iodopropyl)methylsilane) (PFS-I, $M_{\mathrm{w}}: 3.12 \times 10^{5} \mathrm{~g} / \mathrm{mol}, M_{\mathrm{n}}: 1.56 \times 10^{5} \mathrm{~g} / \mathrm{mol}, M_{\mathrm{w}} / M_{\mathrm{n}}: 2.0$ ) was prepared according to established procedures. ${ }^{31}$ Dimethylsulfoxide (DMSO) and tetrahydrofuran (THF) were obtained from Biosolve. Tri- $n$-butylphosphine, dimethylaminopropyl methacrylamide (DMAPMA), 1hexylamine and multi-walled carbon nanotubes (MWCNTs, 6-13 $\mathrm{nm} \times 2.5-20 \mu \mathrm{m}$ ) were obtained from Aldrich and used without further purification. Polyethylene glycol-tetrathiol (4-arm PEG-thiol, pentaerythritol core, $\left.M_{n}=5000 \mathrm{~g} \mathrm{~mol}^{-1}\right)$ was purchased from JenKem Technology, USA. Sodium 1pentanesulfonate $\left(\mathrm{NaC}_{5} \mathrm{~S}\right)$ and sodium 1-hexanesulfonate
$\left(\mathrm{NaC}_{6} \mathrm{~S}\right)$ was supplied by TCI, Belgium. Milli-Q water was used in all experiments.

Characterization Methods. ${ }^{1} \mathrm{H}$ NMR and ${ }^{13} \mathrm{C}$ NMR spectra were acquired with a Bruker Avance III (400 $\mathrm{MHz}$ ) instrument at 400.1 and $100.6 \mathrm{MHz}$, respectively.

Fourier Transform Infrared (FTIR) spectra were recorded with a Bruker ALPHA spectrometer on dried samples.

Turbidity measurements were conducted with a custom built photometer equipped with a $10 \mathrm{~mW} \mathrm{HeNe}$ laser (633 $\mathrm{nm})$, a photodiode amplifier and a handheld digital multimeter; transmittance at $25^{\circ} \mathrm{C}$ was defined as $100 \%$; the healting/cooling rate was $1 \mathrm{~K} \mathrm{~min}^{-1}$.

Dynamic light scattering (DLS): Hydrodynamic radii were measured on a Zetasizer Nano Series (Malvern, Worcestershire, United Kindom).

Rheological experiments were carried out with an UDS 200 rheometer (Anton Paar) using parallel plates $(25 \mathrm{~mm}$ diameter, gap $0.8 \mathrm{~mm}$ ) configuration at $25{ }^{\circ} \mathrm{C}$ in the oscillatory mode.

The swelling ratio (by weight) was calculated as follows: $\left(W_{h}-W_{d}\right) / W_{d}$, where $W_{h}$ and $W_{d}$ were the hydrated and dry sample weights, respectively. The hydrogels were allowed to equilibrate in Milli-Q water for $24 \mathrm{~h}$ until a constant weight was reached. Surface water was carefully wiped off before weighing.

Cyclic Voltammetry (CV) measurements were performed with an Autolab PGSTAT 32. A conventional three-electrode system used included a working electrode (ITO glass substrate), a $\mathrm{Ag} / \mathrm{AgCl}$ reference electrode and a Pt counter electrode.

Synthesis of PFS-PBu 3 -Cl. Tri- $n$-butylphosphine $(750$ $\mu \mathrm{L}, 3.0 \mathrm{mmol})$ and DMSO $(6 \mathrm{~mL})$ were added to a solution of PFS-I ( $0.4 \mathrm{~g}, 1.0 \mathrm{mmol})$ in THF $(12 \mathrm{~mL})$. The mixture was then stirred at room temperature for $24 \mathrm{~h}$. After removing the THF by a flow of $\mathrm{N}_{2}$, the mixture was transferred to a Spectra/Por 4 dialysis hose (MWCO 12$\left.14000 \mathrm{~g} \mathrm{~mol}^{-1}\right)$ and dialyzed against $0.1 \mathrm{M} \mathrm{NaCl}(3 \times 1 \mathrm{~L})$ and Milli-Q water $(3 \times 1 \mathrm{~L})$. Concentration of the salt-free polyelectrolyte solution by a flow of $\mathrm{N}_{2}$ produced PFS$\mathrm{PBu}_{3}-\mathrm{Cl}$ as orange flakes.

Synthesis of PFS-PBu $-\mathrm{C}_{5} \mathrm{~S}$. PFS- $\mathrm{PBu}_{3}-\mathrm{Cl}$ aqueous solution was dialyzed against $0.1 \mathrm{M} \mathrm{NaC}_{5} \mathrm{~S}(3 \times 1 \mathrm{~L})$ and Milli-Q water $(3 \times 1 \mathrm{~L})$. Concentration of the salt-free polyelectrolyte solution by a flow of $\mathrm{N}_{2}$ produced PFS$\mathrm{PBu}_{3}-\mathrm{C}_{5} \mathrm{~S}$ as orange flakes.

Synthesis of PFS-DMAPMA-PBu ${ }_{3}$-Cl. DMAPMA with required molar ratio was added to a solution of PFS-I ( 0.2 $\mathrm{g}, 0.5 \mathrm{mmol})$ in THF $(8 \mathrm{~mL})$ and DMSO $(4 \mathrm{~mL})$. The reaction mixture was susbequently stirred at room temperature for 1 day. Tri- $n$-butylphosphine $(750 \mu \mathrm{L}, 3$ mmol) and additional THF (4 mL) were added to the mixture for the next reaction at room temperature, which proceeded for 1 day. The rest of the THF was removed by a $\mathrm{N}_{2}$ flow and the resulting mixture was dialyzed against o.1 $\mathrm{M} \mathrm{NaCl}(3 \times 1 \mathrm{~L})$ and Milli-Q water $(3 \times 1 \mathrm{~L})$. 
Hydrogel formation. PFS-DMAPMA-PBu 3 with $\mathrm{C}_{5} \mathrm{~S}$ or $\mathrm{C}_{6} \mathrm{~S}$ counterions, and 4-arm PEG-thiol were mixed at the required ratio in water $(500 \mu \mathrm{L})$ in a vial or mold. The concentration of PFS-PEG was $5 \mathrm{wt} \%$ in the mixture. 1Hexylamine (1o $\mu \mathrm{L})$ was added as the catalyst. The time to form a gel (gelation time) was estimated to be $2 \mathrm{~h}$ at room temperature.

Dispersion of CNTs was accomplished by the following procedure. CNTs $(15.0 \sim 25.0 \mathrm{mg})$ were added to Milli-Q water (10.0 mL) containing PFS-DMAPMA-PBu (20.0 mg). The mixture was ultrasonicated in an ice bath for $30 \mathrm{~min}$. The dispersion was concentrated under a flow of $\mathrm{N}_{2}$ and then ready for preparing hydrogels.

CNT-hydrogel composite formation. The conductive hydrogel was prepared in two steps. First, well-dispersed high concentration CNT suspensions with PFSDMAPMA-PBu $\mathrm{P}_{3}$ as dispersant were obtained under a flow of $\mathrm{N}_{2}$ after ultrasonication. Second, the PEG cross-linker 4-arm PEG-thiol and 1-hexylamine were mixed in the CNT suspensions. The concentration of CNTs was $8 \mathrm{wt} \%$ in the pre-gel mixture. After $12 \mathrm{~h}$ crosslinking at $40{ }^{\circ} \mathrm{C}$, a black conductive hydrogel was obtained.

\section{- ASSOCIATED CONTENT}

\section{Supporting Information}

The Supporting Information is available free of charge on the ACS Publications website. NMR, UV-Vis, FTIR spectra, cyclic voltammograms, rheological experiments and turbidity curves of uncross-linked polymer solution. (PDF)

\section{- AUTHOR INFORMATION}

\section{Corresponding Author}

*g.j.vancso@utwente.nl

\section{Present Address}

†Centre for Biomimetic Sensor Science, School of Materials Science and Engineering, Nanyang Technological University, 637553, Singapore.

\section{Author Contributions}

$\ddagger$ K.Z. and X.F. contributed equally.

\section{Notes}

The authors declare no competing financial interest.

\section{- ACKNOWLEDGMENT}

This work was supported by the $\mathrm{MESA}^{+}$Institute for Nanotechnology of the University of Twente and The Netherlands Organization for Scientific Research (NWO TOP Grant 700.56.322, Macromolecular Nanotechnology with Stimulus-Responsive Polymers and NWO 728.011.205, ChemThem: Out-of-Equilibrium Self-Assembly).

\section{- REFERENCES}

(1) Stuart, M. A. C.; Huck, W. T. S.; Genzer, J.; Müller, M.; Ober, C.; Stamm, M.; Sukhorukov, G. B.; Szleifer, I.; Tsukruk, V. V.; Urban, M.; Winnik, F.; Zauscher, S.; Luzinov, I.; Minko, S. Nat. Mater. 2010, 9, 101-113.
(2) Yan, X.; Wang, F.; Zheng, B.; Huang, F. Chem. Soc. Rev. 2012, 41, 6042-6065.

(3) Lu, W.; Le, X.; Zhang, J.; Huang, Y.; Chen, T. Chem. Soc. Rev. 2017, 46, 1284-1294.

(4) Hu, J.; Liu, S. Macromolecules 2010, 43, 8315-8330.

(5) Liu, Z.; Wang, W.; Xie, R.; Ju, X.-J.; Chu, L.-Y. Chem. Soc. Rev. 2016, 45, 460-475.

(6) Lv, J.-A.; Liu, Y.; Wei, J.; Chen, E.; Qin, L.; Yu, Y. Nature 2016, 537, 179-184.

(7) Lutz, J.-F.; Lehn, J.-M.; Meijer, E. W.; Matyjaszewski, K. Nat. Rev. Mater. 2016, 1, 16024.

(8) Roy, D.; Brooks, W. L. A.; Sumerlin, B. S. Chem. Soc. Rev. 2013, 42, 7214-7243.

(9) Wojtecki, R. J.; Meador, M. A.; Rowan, S. J. Nat. Mater. 2011, 10, 14-27.

(10) Schild, H. G. Prog. Polym. Sci. 1992, 17, 163-249.

(11) Lutz, J. F.; Akdemir, O.; Hoth, A. J. Am. Chem. Soc. 20o6, 128, 13046-13047.

(12) Qiao, Y.; Ma, W.; Theyssen, N.; Chen, C.; Hou, Z. Chem. Rev. 2017, 117, 6881-6928.

(13) Kohno, Y.; Saita, S.; Men, Y.; Yuan, J.; Ohno, H. Polym. Chem. 2015, 6, 2163-2178.

(14) Men, Y.; Schlaad, H.; Yuan, J. ACS Macro Lett. 2013, 2 , 456-459.

(15) Men, Y.; Li, X.-H.; Antonietti, M.; Yuan, J. Polym. Chem. 2012, 3, 871-873.

(16) Fan, X.; Liu, H.; Gao, Y.; Zou, Z.; Craig, V. S. J.; Zhang, G.; Liu, G. Adv. Mater. 2016, 28, 4156-4161.

(17) Qian, W.; Texter, J.; Yan, F. Chem. Soc. Rev. 2017, 46, 11241159.

(18) Hailes, R. L. N.; Oliver, A. M.; Gwyther, J.; Whittell, G. R.; Manners, I. Chem. Soc. Rev. 2016, 45, 5358-5407.

(19) Bellas, V.; Rehahn, M. Angew. Chem. Int. Ed. 2007, 46, 5082-5104.

(20) Nguyen, P.; Gomez-Elipe, P.; Manners, I. Chem. Rev. 1999, 99, 1515-1548.

(21) Whittell, G. R.; Hager, M. D.; Schubert, U. S.; Manners, I. Nat. Mater. 2011, 10, 176-188.

(22) Pelegri-O’Day, E. M.; Paluck, S. J.; Maynard, H. D. J. Am. Chem. Soc. 2017, 139, 1145-1154.

(23) Barlow, T. R.; Brendel, J. C.; Perrier, S. Macromolecules 2016, 49, 6203-6212.

(24) Freyer, J. L.; Brucks, S. D.; Gobieski, G. S.; Russell, S. T.; Yozwiak, C. E.; Sun, M.; Chen. Z.; Jiang, Y.; Bandar, J. S.; Stockwell, B. R.; Lambert, T. H.; Campos, L. M. Angew. Chem. Int. Ed. 2016, 55, 12382- 12386.

(25) Sui, X.; van Ingen, L.; Hempenius, M. A.; Vancso, G. J. Macromol. Rapid Comm. 2010, 31, 2059-2063.

(26) Sui, X.; Hempenius, M. A.; Vancso, G. J. J. Am. Chem. Soc. 2012, 134, 4023-4025.

(27) Zhang, K.; Feng, X.; Sui, X.; Hempenius, M. A.; Vancso, G. J. Angew. Chem. Int. Ed. 2014, 53, 13789-13793.

(28) Folkertsma, L.; Zhang, K.; Czakkel, O.; de Boer, H. L.; Hempenius, M. A.; van den Berg, A.; Odijk, M.; Vancso, G. J. Macromolecules 2017, 50, 296-302.

(29) Feng, X.; Sui, X.; Hempenius, M. A.; Vancso, G. J. J. Am. Chem. Soc. 2014, 136, 7865-7868.

(30) Zoetebier, B.; Sohrabi, A.; Lou, B.; Hempenius, M. A.; Hennink, W. E.; Vancso, G. J. Chem. Commun. 2o16, 52, 77077710.

(31) Hempenius, M. A.; Brito, F. F.; Vancso, G. J. Macromolecules 2003, 36, 6683-6688.

(32) Hempenius, M. A. ; Cirmi, C. ; Song, J. ; Vancso, G. J. Macromolecules 2009, 42, 2324-2326.

(33) Li, W.; Wu, P. Polym. Chem. 2014, 5, 5578-5590.

(34) Rulkens, R.; Lough, A. J.; Manners, I.; Lovelace, S. R.; Grant, C.; Geiger, W. E. J. Am. Chem. Soc. 1996, 118, 12683-12695. 
(35) Sui, X.; Feng, X.; Song, J.; Hempenius, M. A.; Vancso, G. J. J. Mater. Chem. 2012, 22, 11261-11267.

(36) Shi, W.; Cui, S.; Wang, C.; Wang, L.; Zhang, X. Macromolecules 2004, 37, 1839-1842.

(37) Shi, W.; Giannotti, M. I.; Zhang, X.; Hempenius, M. A.; Schönherr, H.; Vancso G. J. Angew. Chem. Int. Ed. 2007, 46, 8400-8404.

(38) Zou, S.; Hempenius, M. A.; Schönherr, H.; Vancso, G. J. Macromol. Rapid Commun. 2oo6, 27, 103-108.

(39) Hvidt, S.; Jorgensen, E. B.; Brown, W.; Schillen, K. J. Phys. Chem. 1994, 98, 12320-12328.

(40) Almgren, M.; Brown, W.; Hvidt, S. Colloid Polym. Sci. 1995, 273, 2-15.

(41) Ziolkowski, B.; Diamond, D. Chem. Commun. 2013, 49, 10308-10310.

(42) Schmidt, B. V. K. J.; Kugele, D.; von Irmer, J.; Steinkoenig, J.; Mutlu, H.; Rüttiger, C.; Hawker, C. J.; Gallei, M.; BarnerKowollik, C. Macromolecules 2017, 50, 2375-2386.

(43) Hwang, K.; Kwak, D.; Kang, C.; Kim, D.; Ahn, Y.; Kang, Y. Angew. Chem. Int. Ed. 2011, 50, 6311-6314.

(44) Lee, D.; Nolte, A. J.; Kunz, A. L.; Rubner, M. F.; Cohen, R. E. J. Am. Chem. Soc. 2006, 128, 8521-8529.

(45) Secrist, K. E.; Nolte, A. J. Macromolecules 2011, 44, 28592865 .

(46) Weidman, J. L.; Mulvenna, R. A.; Boudouris, B. W.; Phillip, W. A. J. Am. Chem. Soc. 2016, 138, 7030-7039.
(47) Kim, E.; Kang, C.; Baek, H.; Hwang, K.; Kwak, D.; Lee, E.; Kang, Y.; Thomas, E. L. Adv. Funct. Mater. 2010, 20, 1728-1732.

(48) Annaka, M.; Tanaka, T. Nature 1992, 355, 430-432.

(49) Kim, D.; Kim, H.; Lee, E.; Jin, K. S.; Yoon, J. Chem. Mater. 2016, 28, 8807-8814.

(50) Sambe, L.; de La Rosa, V. R.; Belal, K.; Stoffelbach, F.; Lyskawa, J.; Delattre, F.; Bria, M.; Cooke, G.; Hoogenboom, R.; Woisel, P. Angew. Chem. Int. Ed. 2014, 53, 5044-5048.

(51) Mori, T.; Beppu, S.; Berber, M. R.; Mori, H.; Makimura, T.; Tsukamoto, A.; Minagawa, K.; Hirano, T.; Tanaka, M.; Niidome, T.; Katayama, Y.; Hirano, T.; Maeda, Y. Langmuir 2010, 26, 92249232.

(52) Löwenberg, C.; Balk, M.; Wischke, C.; Behl, M.; Lendlein, A. Acc. Chem. Res. 2017, 50, 723-732.

(53) Suzuki, A.; Ishii, T.; Maruyama Y. J. Appl. Phys. 1996, 8o, 131-136.

(54) Soll, S.; Antonietti, M.; Yuan, J. ACS Macro Lett. 2012, 1, $84-87$.

(55) Li, Y.; Li, G.; Wang, X.; Zhu, Z.; Ma, H.; Zhang, T.; Jin, J. Chem. Commun. 2012, 48, 8222-8224.

(56) Wu, B.; Hu, D.; Kuang, Y.; Liu, B.; Zhang, X.; Chen, J. Angew. Chem. Int. Ed. 2009, 48, 4751-4754.

(57) Fukushima, T.; Kosaka, A.; Ishimura, Y.; Yamamoto, T.; Takigawa, T.; Ishii, N.; Aida, T. Science 2003, 300, 2072-2074.

(58) Guo, K.; Zhang, D. L.; Zhang, X. M.; Zhang, J.; Ding, L. S.; Li, B. J.; Zhang, S. Angew. Chem. Int. Ed. 2015, 54, 12127-12133. 


\section{For Table of Contents Only}

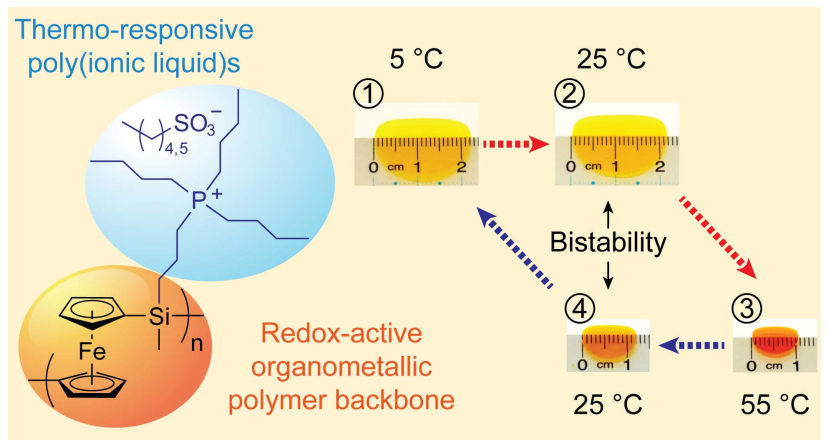

